\title{
DISCURSOS QUE CIRCULAM NA CORREC̦ÃO DE UM QUESTIONÁRIO: SENTIDOS E SIGNIFICADOS
}

\begin{abstract}
RESUMO: Este trabalho analisa o uso do questionário em uma aula de Ciências nas séries iniciais do Ensino Fundamental. Ao investigar a aula, compreendemos o questionário como um gênero escolar pertencente a práticas institucionalizadas que envolvem alunos e professores a partir de contratos tácitos que vinculam as duas pontas na interação, numa incessante tarefa de produção de sentido a partir do querer dizer do professor e do que é interpretado pelos alunos. Baseado em estudos sobre esse gênero, foram analisados três episódios distintos que contemplam diferentes fases da correção de um questionário. Num primeiro momento, os papéis desempenhados por professora e alunos e o lugar social de onde falam, ouvem e agem é bem marcado. No segundo evento, identificamos que no processo de correção do questionário, a linguagem não se apresenta ordenada. Como produto do incessante leva e traz, o discurso resiste a uma sistematização rígida. No último evento, identificamos que mesmo com as opressões hierárquicas, as palavras circulam. Assim, partindo dos pressupostos bakhtinianos, a questão fundamental presente neste artigo é a discussão da natureza dialógica do questionário.
\end{abstract}

Palavras-chave: Questionário; Dialogia; Ensino de Ciências; Sala de Aula.

\section{DISCOURSES PRESENT IN THE CORRECTION OF A QUESTIONNAIRE: SENSES AND MEANINGS}

ABSTRACT: This work analises the use of questionnaires in a primary Science classroom. We applied the questionnaires as a school genre, belonging to institutionalized practices among students and teachers which are carried out from tacit contracts that link both sides of the interaction. Based on the study of such genre, we have analysed three episodes concerning three different steps of the questionnaire correction. In the first instance, the roles played by the teacher and the students, as well as the social milieu from which they speak, hear and act are well defined, contrary to what happened in the second episode. As a product of a ceaseless movement, the discourse resists to a rigid systematization. In the last episode, we have identified that the words move on, in spite of the hierarchical oppressiveness. Therefore, from bakhtinian perspective, the fundamental question of this article is the discussion of the dialogical nature of the questionnaire.

Keywords: questionnaire, dialogism, Science teaching, classroom.

\author{
Sheila Alves de Almeida* \\ Marcelo Giordan** \\ *Doutora em Educação \\ pela Universidade de são \\ Paulo (USP). Professora \\ do Departamento de \\ Biodiversidade, Evolução e Meio \\ Ambiente da Universidade \\ Federal de Ouro Preto (UFOP) \\ Email: sheilaalvez@iceb.ufop.br \\ * *Doutor em Química pelo \\ Programa de Pós-graduação \\ em Química no Instituto de \\ Química da Universidade de \\ Campinas(IQ-UNICAMP). \\ Professor da Faculdade de \\ Educação da Universidade de \\ São Paulo(USP). \\ Email: giordan@usp.org.br
}


Uma só voz nada termina, nada resolve. Duas vozes são o mínimo de vida. (BAKHTIN)

\section{INTRODUCุÃO}

As reflexões apresentadas neste trabalho têm a intenção de analisar os discursos que circularam a partir de uma aula cujo objetivo era a correção de um questionário no ensino de Ciências nas séries iniciais.

Apesar de o questionário se constituir como uma prática pedagógica muito presente em todos os níveis de ensino da educação básica, as pesquisas em educação pouco se detêm nas interações pedagógicas que ocorrem com o uso dessa estratégia. Essa prática comporta uma série de relações entre quem pergunta, quem responde, como é realizada a pergunta, como é a resposta, bem como o conteúdo dessas perguntas e respostas.

O questionário nas aulas de Ciências pode ser uma ferramenta importante que possibilita a reflexão e tomada de consciência da linguagem científica. Nas séries iniciais, as crianças, frequentemente, colocam a sua opinião sobre o que acham ser verdade a partir de uma pergunta lançada pelo professor. Dessa forma, o questionário pode ser uma ferramenta capaz de ensiná-las a construir uma lógica e não apenas uma suposição, à medida que a sua utilização em sala de aula seja estruturada em uma dinâmica discursiva apropriada.

Em seu breve histórico, os Parâmetros Curriculares Nacionais apontam que o ensino de Ciências no Ensino Fundamental tem se orientado por diferentes tendências, que se expressam por um leque multifacetado de práticas pedagógicas em sala de aula (BRASIL, p.19, 1998). Esse documento aponta que algumas práticas atravessam a história dessas tendências. O questionário, nas séries iniciais, e nas aulas de Ciências, é um dos recursos de estudo e avaliação mais utilizado. Assim, ao analisar o uso do questionário, pretendemos evidenciar, entre outros aspectos, as formas discursivas de mediação que constituem as interações e suas repercussões nas aulas de Ciências das séries iniciais. Buscamos, no vivido, estreitar o diálogo entre a dinâmica interativa de ensinar e aprender e uma teoria do discurso que permite analisar como as ideias são fortalecidas, ignoradas, censuradas, e como ocorre (ou não) a construção do conhecimento científico no contexto escolar tendo em vista os tensionamentos existentes entre as vozes na sala de aula. Nessa perspectiva, procuramos auxílio, especialmente, nas teorias de Bakhtin (1995, 1997, 1981), Vygotsky (1993, 1994), Mortimer e Scott (2003), Cazden (2001), Candela (1999) e Rojo (2007), autores que nos auxiliam na compreensão do discurso e das práticas discursivas nas aulas de Ciências. Baseados nos estudos desses autores, a questão fundamental que se apresenta neste trabalho é como o diálogo é construído em uma aula cujo objetivo é a correção de um questionário sobre a transformação da matéria-prima. Interessa-nos compreender a natureza dialógica do questionário - como as crianças, participantes na cadeia discursiva, constroem seus enunciados em função das perguntas e respostas, sentidos e significados que circulam durante a aula. 
Embora a formação das professoras das séries iniciais, o conteúdo e a metodologia sejam elementos passíveis de análise, neste trabalho o nosso foco recai sobre as relações de poder presentes no discurso e a construção de sentidos e significados no território comum da palavra no uso do questionário.

\section{QUADRO TEÓRICO}

As proposições de Silveira (1966) sobre o uso do questionário apresentam aspectos peculiares à discussão dessa estratégia. Apesar de distante no tempo, o livro de Silveira se justifica porque nele encontramos orientações e uma concepção explícita de aprendizagem que parece estar na vivência de muitas gerações que aprenderam e aprendem com o questionário. A autora orienta que a leitura das crianças deve anteceder o questionário a serviço de uma "racionalização" da leitura. Dessa forma, o questionário habilita ao leitor a seleção e apropriação das informações mais relevantes do texto. Para Silveira (1966), o questionário é um recurso de avaliação capaz de comprovar a capacidade de compreensão. Assim, são os objetivos da aula que devem orientar o professor na elaboração das questões, ora visando à compreensão literal, ora à capacidade de interpretação, ora à de crítica, ora à de utilização dos conhecimentos em diferentes graus de dificuldade (p.271). Conforme a autora, o questionário também pode ser apresentado antes da leitura para conduzir o pensamento do leitor. Silveira (1966) sugere o questionário como um recurso que pode ser aplicado oralmente ou por escrito, sendo o registro o mais aconselhado para comparar, posteriormente as respostas. Coerente com a psicologia da gestalt, o questionário, para essa autora, é um instrumento que ensina às crianças a analisar para melhor compreender, pois compreensão é síntese, segundo a gestalt. Nessa perspectiva, o questionário é um recurso pedagógico que possibilita um extraordinário poder de síntese.

Em sua investigação sobre a estrutura da conversação e atos de fala na sala de aula, Mehan (1979) conclui que a interação professor/aluno pode ser analisada segundo o padrão triádico, identificado como I-R-A: Iniciação do professor, Resposta do aluno e Avaliação do professor. Nessa perspectiva, podemos observar que o questionário é uma estratégia didática que busca sustentar esse tipo de interação identificado por Mehan. Nas aulas mediadas pelo questionário, as sequências de interação se alternam até que o professor obtenha a resposta pretendida e feche a cadeia com uma avaliação. Considerando os padrões triádicos de interação, Mehan apontou quatro tipos de iniciação, por ele denominadas de: elicitação de escolha, elicitação de produto, elicitação de processo e elicitação de metaprocesso. Cada tipo de iniciação formulada pelo professor é seguido por um tipo específico de resposta. De acordo com Mehan (1979, p. 43), "a elicitação de escolha demanda ao respondente que concorde ou discorde com uma afirmação feita pelo perguntador". A iniciação de produto (1979, p. 44) “[...] demanda ao respondente uma resposta factual como um nome, um lugar, uma data, uma cor”. A elicitação de 
processo (1979, p. 45) “[...] demanda a opinião ou interpretação do respondente". O quarto tipo de elicitação, por sua vez, a iniciação de metaprocesso (1979, p. 46), "demanda aos estudantes que sejam reflexivos sobre o processo de estabelecer conexões entre elicitações e respostas". Em seus trabalhos, Mehan chama a atenção para as demandas de escolha ou produto que tendem a elicitar respostas curtas constituídas por uma única palavra, que são avaliadas pelos professores, gerando sequências do tipo I-R-A.

A partir dos estudos de Mehan, podemos observar que o questionário apresenta esse padrão, pois por meio dele o professor interage a partir das perguntas, comprova o acompanhamento e confirma o entendimento dos alunos na correção. No movimento dialógico, as perguntas do questionário se destacam na escolha de determinadas palavras para iniciar as perguntas; frequentemente as palavras são pensadas a partir de demandas de escolha ou produto, iniciadas com quem?, quando?, quanto?

O trabalho de Weissmann, fruto de pesquisas realizadas na Dirección de Planeamiento-Educación e na Universidade Nacional de Luján, é uma contribuição diferenciada entre os estudos que abordam as práticas pedagógicas nas aulas de Ciências por se tratar de uma pesquisa de base sobre as estratégias de ensino e suas contradições. O objetivo sistematicamente reafirmado ao longo do texto é a busca de fundamentos para esclarecer a congruência entre o que alguns professores dizem ensinar, dizem querer ensinar e finalmente ensinam. Seu foco está na discussão de algumas práticas muito comuns nas aulas de Ciências, dentre elas as formas de intervenção baseadas no questionamento.

Ao discutir o fazer pedagógico nas aulas de Ciências, Weissmann (1998) afirma que o trabalho com texto seguido de uma série de perguntas constitui uma das propostas de intervenções mais frequentes em sala de aula. Para a autora, essa prática esconde um modo de intervenção transmissivo cuja finalidade única é desenvolver a habilidade do aluno de encontrar a informação solicitada. Weissmann critica o uso do questionário ao constatar que nessa prática o aluno apenas transcreve as respostas do texto, tal qual aparece no livro. Ressalta, ainda, que o professor evita aulas expositivas fugindo do rótulo da "aula tradicional". As aulas baseadas no questionamento são valorizadas pelos professores que vivem a ilusão de uma aula ativa com pouco ou nenhum material experimental. Dessa forma, recorrem a esse tipo de estratégia por considerá-la "ativa e participativa". Na opinião da autora:

Essa 'ilusão interrogativa' considera, obviamente, que o conhecimento está dentro do aluno e que a habilidade do docente consiste em poder desfazer e voltar a tecer uma nova trama. Essa estratégia possui a particularidade de que, sendo a interação docente/aluno uma interação radial, ou seja, não havendo praticamente interação alguma entre os conhecimentos dos alunos, quem finalmente pode organizar essa trama é o próprio docente mas, nenhum dos alunos em particular (WEISSMANN,1998, p.42).

Para Weissmann, nessa forma de intervenção baseada no questionamento, o professor pergunta, verifica se a resposta contém a palavra esperada, 
segue adiante; se não, ignora a resposta ou corrige e continua perguntando (p.46). Para a autora, o questionário condiciona as relações entre alunos e professores, pois no fluxo da interação determina quem fala e quem responde. A extensa lista de perguntas sequenciais impõe um "diálogo" sem retorno, uma vez que o questionário, com sua exigência de organização hierárquica e disciplinada das ideias, contraria o fluxo natural do pensamento. Ao questionar sobre o saber presente nessa estratégia de perguntas e respostas, Weissmann afirma que se pode constatar expressões que soam como "científicas", mas sem garantias em relação à qualidade e ao grau de apropriação pelo aluno.

O texto de Weissmann apresenta-se, assim, como valioso instrumento de compreensão do questionário nas aulas de Ciências e também como orientação para refletir a formação docente. São contribuições oportunas, significativas e legítimas que nos leva a pensar: "Qual é o papel do questionário nas aulas de Ciências?" "É a forma de intervenção ou é o conteúdo de ensino que determina a aprendizagem?” "Como os alunos interagem com essa estratégia didática?".

Em outra direção, Mortimer e Scott (2003) apontam a necessidade de tornar visíveis as práticas discursivas existentes em sala de aula. Para os autores, a ênfase no discurso e na interação tem sido pouco discutida entre professores e investigadores da área; no entanto, elas dão suporte para a compreensão sobre os processos pelos quais os alunos constroem significados em sala de aula. Segundo os autores, o ingresso na linguagem científica é como a entrada em uma nova cultura, diferente da cultura do sentido comum, em que o professor possui um papel fundamental como representante da cultura científica. Assim, em um de seus artigos, Mortimer e Scott (2003) enfatizam a importância da forma com que o professor intervém nas discussões com seus alunos. Nesse trabalho, os autores mostram uma aula baseada em questionamento em que a professora ensina o processo da ferrugem aos alunos. As perguntas da professora conduzem os alunos à construção de um pensamento científico. Segundo os autores, a professora faz perguntas que estimulam os alunos pensarem, assim os estudantes são capazes de articular suas ideias em palavras. Os alunos não falam livremente, encontram um equilíbrio entre a livre apresentação de ideias e a atenção às questões já discutidas. Nesse processo, observamos que as perguntas da professora são tão importantes quanto as respostas que se espera receber dos alunos.

Para esses autores, conhecemos pouco sobre como os professores dão suporte ao processo pelo qual os alunos constroem significados em salas de aula de Ciências, sobre como essas interações são produzidas e sobre como os diferentes tipos de discurso podem auxiliar a aprendizagem dos estudantes.

Essas questões vão adensando a importância de compreender os processos interacionais constituídos por estudantes e professores em torno de aulas com o uso do questionário. Em relação ao questionário, entendemos essa prática como um tipo particular de interação escolar e como veiculador de sentidos. Dessa forma, uma das tarefas importantes para a nossa reflexão é precisamente extrair da dinâmica interativa dessa prática sua polissemia e sua discursividade. Com isso, 
postula-se que o questionário não é um simples ato de perguntas e respostas. As perguntas e respostas do questionário fazem parte da construção do sentido, ele é, também, ato de linguagem, ato de significação, para quem pergunta e para quem responde. É nessa perspectiva que este estudo procura avançar.

\section{O QUESTIONÁRIO: ASPECTOS DE UM GÊNERO ESCOLAR}

Segundo Bakhtin (1995), a enunciação é produto da relação social, e qualquer enunciado fará parte de um gênero. Assim, para esse autor (1979), os gêneros são aprendidos no curso de nossas vidas como participantes de determinado grupo social ou membro de alguma comunidade. Logo, os gêneros podem ser considerados padrões comunicativos que socialmente utilizados funcionam com uma espécie de modelos comunicativos globais que representam em conhecimento social localizado em situação concreta. Para Bakhtin, as diferentes esferas sociais de conhecimento estão relacionadas à utilização da língua e constituem-se como linguagens sociais. Isto é, cada esfera social de conhecimento se relaciona a uma discursividade, caracterizando um determinado modo de conhecer os aspectos da realidade e de explicá-los.

Por estarem inseridos em diversas esferas sociais, os gêneros não são conservadores, mas estão em contínua transformação no mesmo instante em que buscam garantir uma certa estabilização.

“O gênero sempre é e não é o mesmo, sempre é novo e velho ao mesmo tempo. O gênero renasce e se renova em cada nova etapa do desenvolvimento da literatura e cada obra individual de um dado gênero. Nisto consiste a sua vida" (Bakhtin,1981, 91)

Nessa perspectiva, os gêneros são duplamente determinados pelos sentidos do discurso e pelas formas, significados e construções de um gênero específico. Para classificar determinado enunciado como pertencente a dado gênero, é necessário que verifiquemos suas condições de produção, circulação e recepção. E, ainda, é de extrema relevância observar que o gênero, como fenômeno social que é, só existe em determinada situação comunicativa e sócio-histórica.

Devido à extrema heterogeneidade dos gêneros do discurso, resultado da infinidade de relações sociais que se apresentam na vida humana, Bakhtin dividiu os gêneros em dois tipos: gênero de discurso primário e gênero de discurso secundário. Os chamados gêneros primários se constituem em circunstâncias de uma comunicação verbal espontânea, e são a base para a constituição dos gêneros secundários. Os gêneros secundários são aqueles que emanam das situações, para os quais existe um meio para que sejam configurados. Esse meio é, normalmente, a escrita.

Schneuwly e Dolz (1999), em seus estudos sobre gêneros orais e escritos, identificam que as situações de ensino e aprendizagem deixam marcas de uma linguagem específica que se cristaliza no uso do contexto de sala de aula. Esses 
autores chamam a atenção para o fato de que a escola, na sua tarefa de ensinar a ler e escrever, não faz dos gêneros um instrumento de comunicação, mas uma prática de linguagem instaurada com fins de aprendizagem. Em razão disso, o gênero, instrumento de comunicação transforma-se em forma de expressão do pensamento, da experiência ou da percepção (p.9). Ao abordar os textos dessa forma, a escola escolariza os gêneros e acaba por ensinar "autênticos produtos culturais da escola" - gêneros escolares.

Nas séries iniciais, dentre os gêneros escolares alguns são de uso frequente e quase exclusivo da escola: as listas de chamada, a lista de combinados da turma, o cartaz de aniversariante, o cartaz dos ajudantes do dia, a avaliação oral, a prova, as anotações de aula, o questionário, etc.

As perguntas do questionário são apresentadas em uma disposição que mantém um padrão uniforme. Quando registrado, a sua estrutura composicional possui quase sempre um título: "Questionário" e uma lista de perguntas, em geral numeradas. As perguntas frequentemente giram em torno de um assunto estudado pelos alunos. A partir da escrita do título no quadro, os alunos já sabem como proceder: copiam as perguntas, consultam o livro para as respostas para a correção coletiva. O horizonte temático do questionário refere-se a questões próprias do universo da enunciação de cada disciplina. Em geral, as perguntas sucedem ao ensino.

A emergência do questionário é motivada pela necessidade do professor de "fixar a aprendizagem" ao mesmo tempo em que avalia o aluno. Apesar de se apresentar a partir de perguntas, a finalidade discursiva do questionário em sala de aula não se orienta para o debate, mas para a apreciação do professor para a resposta do aluno. Para responder, o aluno precisa "estar por dentro" do tema que está sendo tratado.

O questionário, como gênero escolar, apresenta certas peculiaridades no discurso. Para Rojo (1999), a sala de aula se caracteriza pela presença de um gênero escolar do discurso difícil de situar que intercala gêneros primários e secundários e que hibridiza vozes e linguagens sociais. $\mathrm{Na}$ sala de aula, o objetivo das perguntas do questionário é fazer com que o aluno se aproprie de determinados conceitos. Portanto, o trabalho da escola, com as tarefas como o questionário, inclui essa tentativa de levar às crianças a apropriação dos gêneros secundários. Por meio do questionário, a voz da professora aparece refratada, enunciando-se de vários lugares ou posições. Nesse mosaico enunciativo das linguagens sociais, as perguntas apresentadas no questionário podem ser a pergunta de um livro didático, do professor, ou mesmo dos dois intercalados. Dessa forma, as ideias do professor não está realizada no discurso direto, mas por meio das perguntas mediadas pelo questionário. Pela situação de interação, os alunos interpretam as perguntas de um gênero escolar que se faz passar como científico.

No discurso escolar, aparece também o movimento de distanciamento cujo objetivo é desautorizar o discurso do aluno. No caso do questionário, esse distanciamento acontece no uso de palavras e expressões avaliativas pelo professor. As perguntas do questionário por si só já são avaliativas. Nesse caso, o professor coteja as perguntas com as respostas dos alunos a fim de lapidar e introduzi-los no discurso 
escolar. A resposta certa é a alma dos gêneros escolares. Um outro traço do questionário, comum às práticas pedagógicas, é que a interação professor/aluno acontece no mesmo espaço e tempo físico, mas a elaboração e execução geralmente não ocorrem.

O reconhecimento do questionário outorga tanta credibilidade à fala do professor a ponto de os alunos se permitirem serem questionados mesmo desconhecendo a fonte que originou cada pergunta. Os alunos legitimam o trabalho avaliativo do professor na interação mediada pelo questionário. Os questionários extraídos dos livros didáticos expressam um "valor" que se manifesta no suporte e no conteúdo dos enunciados. Nesse caso, não podemos deixar de mencionar a posição de autoria inscrita no próprio gênero - o questionário do livro da página tal. Por meio do questionário o professor incorpora a aura de competência sociodiscursiva porque ancora seu ponto de vista em um instrumento que é também argumento de autoridade que se manifesta em situações do discurso escolar.

\section{METODOLOGIA}

Com o objetivo de analisar as interações mediadas pela prática do questionário, recorremos a uma aula singular na qual linhas e traços comunicativos, conteúdo e forma, são elementos que reluzem. O evento extraído dessa aula compõe parte dos dados não analisados da dissertação de mestrado: Ver o invisivel: as metamorfoses do aprender e do ensinar ciências em uma experiência de professoras do primeiro ciclo (Almeida, 2005).

A escola onde foi realizada a pesquisa está localizada na periferia da cidade de Belo Horizonte e, ao longo dessas últimas três décadas, oferece ensino para o primeiro e segundo ciclos, nos turnos da manhã e da tarde. A maioria das crianças que frequenta a escola é assistida por programas sociais. A professora havia se formado em Pedagogia fazia menos de dez anos e há onze anos fora nomeada professora na Rede Municipal de Belo Horizonte. Há dez anos atuava com Matemática e Ciências nas séries iniciais. Era professora de aproximadamente cem alunos do primeiro ciclo, distribuídos em quatro salas. Em cada uma das salas, trabalhava duas horas-aula semanais. Os livros didáticos e as discussões no grupo de professoras daquela escola eram fontes de inspiração e guia para seu planejamento.

Os procedimentos metodológicos incluíram registros em vídeo, notas de campo e gravações em áudio de reuniões com a professora. Por tratar-se de um trabalho com o propósito de investigar a compreensão que as professoras das séries iniciais foram construindo acerca das ciências e do seu modo de ensinar, acompanhamos uma sala de aula durante quatro meses, gravando cerca de quinze aulas. Observações dos vídeos indicam que do total das aulas filmadas, em dez aulas a professora usou o questionário como recurso didático.

Para a análise dos dados da aula em que ocorre a correção de um questionário, inspiramo-nos, principalmente, nos construtos teóricos da psicologia histórico-cultural e dos estudos da linguagem, particularmente a teoria da enunciação de 
Bakhtin. Segundo esses referenciais, a atividade do sujeito, longe de ser vista como ação de um indivíduo isolado, é percebida na interação, sendo sempre mediada pelos signos linguísticos, que são construídos cultural e historicamente também nas interações sociais. Adotando aspectos da análise microgenética, procuramos examinar o desenvolvimento das atividades propostas pela professora.

A escolha desse episódio se justifica por considerarmos que nele ocorrem eventos-chave que apontam para indícios recorrentes da prática pedagógica de correção de questionário.

\section{ANÁLISE}

A aula cujo objetivo era a correção de um questionário sobre a transformação da matéria-prima, foi ministrada para crianças de oito e nove anos que já sabiam ler e escrever. Em suas aulas, a professora ficava sempre de pé, segurando um caderno no qual estava traçado seu planejamento, seus questionários, suas anotações. As carteiras eram enfileiradas e todos levantavam a mão para falar. $\mathrm{O}$ contexto inicial da correção dos questionários era marcado por uma rotina que incluía a organização da turma. As palavras de ordem: "atenção para a chamada" marcava o início da leitura de cada nome e era compreendido pelas crianças como um sinal de que permanecessem sentados e em silêncio. Ao término desse ritual, a professora ordenava que as crianças abrissem seus cadernos indicando que faria a correção do questionário. Enquanto procuravam o questionário, algumas crianças retomavam a conversa e outras se levantavam para apontar o lápis ou solicitar algum material emprestado até que a professora indicava o início da tarefa: Pergunta número um... Naquele momento, aos seus lugares, as crianças se apressavam na busca pelo questionário se ajeitando na carteira, com olhos fixos no caderno.

A seguir, apresentamos parte de uma dessas aulas dividida por sequências discursivas extraídas do evento de correção do questionário. A transcrição dos episódios privilegia a trama interacional dos sujeitos que se expressam oralmente diante do questionário. A transcrição é constituída de 67 turnos de fala. Desse total de turnos, 31 correspondem a intervenções da professora e 36 correspondem a intervenções dos alunos. O evento foi dividido em três sequências discursivas. $\mathrm{Na}$ primeira sequência - turno 1 a 16 -, evidenciamos a professora tentando fazer com que as crianças cumprissem a demanda planejada - o discurso de autoridade presente na aula. Na sequência 2 - turno 17 a 35 - o foco discursivo foi a subversão das crianças na dinâmica discursiva, o discurso persuasivo proposto pelas crianças. A sequência 3 - turno 36 a 69 - foi dedicada à discussão dos sentidos e significados presentes em sala de aula. Vejamos então, a primeira sequência ${ }^{2}$ :

\section{Episódio 1: 0 leiteiro e o vaqueiro.}

01. P: Quem tira o leite da vaca?

02. A: Leiteiro 
03. P: Leiteiro distribui o leite. Quem tira o leite da vaca é o...?

04. As: Vaqueiro.

05. A: Professora, a mãe da minha colega ganhou neném e o peito dela inflamou. Ela tinha que colocar uma coisa para o leite sair...

06. P: Tá bom. Onde essa atividade é desenvolvida?

07. A: Coloquei na roça

08. P: Quem fez diferente? A sua resposta está completa?

09. $A:(.$.

10. P: Quem trabalha no processamento do leite?

11. As: Funcionários da indústria.

12. P: TÁ CERTO!

13. A: Coloquei trabalhadores

14. P: TRABALHADORES DA...

15. As: Indústria

16. P: Porque trabalhadores pode ser qualquer um.

\section{VOZES EMUDECIDAS PELO QUESTIONÁRIO?}

Podemos observar nos turnos 1, 8 e 10 a tendência de elicitações de produto descritas por Mehan. Assim, o questionário busca disciplinar o discurso das crianças ditando-lhes regras sobre o quê e como falar do assunto abordado. A escolha do questionário como prática pedagógica que convoca a obediência impõe um discurso de autoridade. Nesse caso, é importante para a professora separar as explicações de sala de aula das experiências familiares, como também já foi observado por Rojo. Assim, no turno 5, o comentários da criança sobre experiências pessoais que aparecem ao longo da correção do exercício não modifica a assimetria da dinâmica discursiva que a professora determina ao longo da interação.

No turno 8 a professora busca uma outra resposta para que todos cheguem às mesmas conclusões. A resposta "errada" ou incompleta é entendida como desvio daquilo que foi posto como regra, uma distorção a ser corrigida, como indicada os turnos 7 e 14. Com apenas uma resposta certa, o questionário é o meio para se chegar à verdade e a professora é sua porta-voz. Os alunos, questionados, procuram corresponder às expectativas da professora quando as respostas são divergentes, como observamos nos turnos 7 e 8, em que eles não insistem em argumentar a favor de suas ideias. Um aspecto importante discutido por Mehan (apud Silva, 2008) refere-se a como os alunos adquirem, ao longo do tempo, competência em se apropriarem desses padrões, respondendo, apropriadamente, no tempo e na forma, e não somente em conteúdo, às questões do professor.

E quando as crianças respondem a partir do que pensam, a professora não só fornece pistas para a correção das ideias das crianças como busca a resposta de uma criança que ela considera correta - turno 8. Nessa perspectiva, a existência de uma resposta é a razão para colocar as perguntas. Cada pergunta gera uma resposta 
que só tem sentido para a escola. Não é em função dos enunciados já ditos que se constrói as perguntas do questionário. O que vemos no turno 12 é um marcador muito presente na sala de aula: “Tá certo!". Esse é um sinal de aprovação discursiva que procura preservar a concordância e a harmonia na sala de aula.

Para Courtney Cazden (1989), a estrutura IRE é uma característica dos discursos institucionais e constitui uma tentativa de controle, uma vez que é o professor que inicia os temas; quem pergunta e quem avalia as respostas. Cazden chama a atenção para o fato de que os professores utilizam formas discursivas para adequar as respostas dos alunos às perguntas que espera que eles respondam. A correção acaba sendo um jogo em que o aluno precisa adivinhar o que o professor espera ouvir.

Nessa sequência - turnos 8 a 16 - a professora, em cada instante, tenta sacralizar a linguagem, destilando-a de todas as "impurezas" de seu uso dialógico. Assim, como vimos em Mehan e Cazden, o questionário é, para a professora, uma prática privilegiada, já que seu projeto discursivo visa a uma atitude responsiva, de concordância com o seu enunciado.

No turno 10, a professora quer saber quem trabalha no processamento do leite. Um aluno responde corretamente e escuta da professora uma expressão de aprovação. No turno 13, outro aluno que, aos olhos da professora, não fornece uma resposta completa para a pergunta, é corrigido no turno 14 pela professora que, ao não escutar a resposta esperada, constrói uma frase lacunar e, de forma mais ou menos explícita, descarta a resposta do aluno. Assim, a professora direciona o grupo para a resposta aceitável. Com esse gesto, a professora adota um ponto de vista e não legitima o ponto de vista das crianças. A palavra da professora pode, num extremo, conceder um espaço extraordinário à palavra de alguma criança e pode, num outro extremo, ignorar completamente outras. E entre um e outro extremo, temos as nuances que estabelecem a relação de força no enunciado. O que percebemos, aqui, é a linguagem como um campo de batalha social, conforme indicado por Bakhtin. A dinâmica interativa presente nesse primeiro fragmento mostra como a linguagem entra nos arranjos hierárquicos de poder. Cada palavra transforma-se na arena onde competem as entonações sociais. A professora se dirige às crianças distribuindo as falas, censurando, distorcendo, ignorando e endossando.

Contudo, embora a professora tenha a intenção de ensinar e para isso procure respostas aceitáveis para as suas perguntas, as crianças saem do script, invadem os ouvidos da professora com perguntas e comentários trazendo à tona uma "aula paralela", como evidenciamos a seguir.

\section{Episódio 2: Eu quero falar!}

17. A: Por que que quando eu fui na roça tinham uns meninos lá de três anos que estavam tirando leite da vaca e quando eu pedi eles não deixaram eu tirar?

18. P: Eles já estavam acostumados e nem conheciam você

19. P: Quem faz o transporte do leite até as fábricas?

20. A: O caminhão 
21. P: Eu perguntei "QUEM", gente!

22. As: $O$ caminhão

23. $P$ : O caminhoneiro

24. A: Quando eu fui pra Bocainuva tinha uma coisa no meio da estrada, aí o caminhoneiro passou e quase caiu lá embaixo, no barranco.

25. P: Ahan...

26. P: Onde o leite empacotado é vendido?

27. A: Nas padarias

28. A: No supermercado

29. P: O leite Longa Vida muitas vezes é comercializado em sacolões porque ele não precisa ser refrigerado.

30. A: O leite é misturado com água.

31. A: Ab! Então não vou tomar mais não!

32. A: Ô professora, eu tava indo para Diamantina, o caminhão saiu rolando...

33. A: Lá em Bocaiúva... (EU QUERO FALAR!)

\section{O “BANQUETE SONORO” PRESENTE NO QUESTIONÁRIO}

Esse "varal de vozes" que insiste em manter uma aula paralela - turnos 30 a 33, com comentários que cortam o curso contínuo das perguntas e respostas do questionário, produzem contra-palavras e buscam sentido para e pelo questionário. A todo o momento, os alunos estão interagindo, produzindo diálogos, os quais possibilitam estar em constante contato com seus interlocutores. Isso significa que as crianças não recebem uma resposta pronta, em vez disso ingressam numa corrente móvel de comunicação verbal.

Para Bakhtin, a linguagem é arena de luta, é inseparável da questão do poder. Portanto, a sala de aula é também uma arena de conflitos de vozes. E o questionário é uma prática pedagógica privilegiada que institui encontros e confrontos. A análise dessa sequência mostra que a participação dos alunos se manifesta para além das respostas previamente definidas do questionário. Um número maior de alunos apresenta suas experiências pessoais a fim de estabelecer relações, exprimir sentimentos e sensações e, em alguns turnos, subvertem a alternância didática entre professora e alunos - turnos 17, 24, 30 a 33. Conforme Bakhtin, essa sequência mostra o enunciado como parte integrante de um diálogo ininterrupto, não como uma voz que responde mecanicamente a outra voz, mas como uma voz que traz em si uma concepção, a perspectiva do outro, a intenção e o ponto de vista do outro, a entoação alheia.

Em seus estudos, Candela (1999) identifica a inversão ou mesmo a subversão das crianças ao padrão IRF. No turno 24, um aluno fala de uma experiência pessoal e a professora ignora seu comentário. Ignorar os comentários e histórias que aparecem na hora da correção do questionário parece ser uma estratégia da professora para manter sua posição e seguir com o controle da turma. Mas, os 
alunos falam e encontram repercussão entre seus pares - turno 30 e 31. Segundo Candela (1999), as crianças apresentam uma tendência de fazer uso de seus conhecimentos para dialogar com outros contextos, o que também pode ser evidenciado nos turnos 17, 24, 30 e 31 .

Essa sequência aponta para as disputas no controle do discurso. Além da subversão do padrão discursivo, as crianças se manifestam com mais frequência do que na primeira sequência. Do total de 17 turnos, os alunos se manifestam em 10. Nos turnos 30 e 31, os alunos se alimentam da palavra da professora para criar outro discurso. Perguntas do tipo produto aparecem nessa sequência apenas uma vez - turno 19. E é exatamente nessa pergunta que a professora explicita quão exata deve ser a resposta. Dizer que o caminhão faz o transporte é menos correto do que dizer que é o caminhoneiro. Já no turno 26, em que a pergunta é iniciada por "onde...", respostas diferentes são aceitas, apesar de também se tratar de uma pergunta de produto.

Esse fragmento mostra de maneira mais evidente como o discurso é perpassado por outros discursos, compondo as várias notas melódicas. No turno 24, enquanto o aluno comenta suas experiências pessoais, inspirado no tema da aula, a professora dá prosseguimento às perguntas do questionário. O discurso das crianças aparece de tal forma que não reproduzem mais as respostas do questionário, mas se tornam donos de seus próprios discursos; é como se acontecesse outras aulas dentro da aula, cada qual com a sua visão sobre o tema em estudo.

E o fim dessa sequência é marcado justamente por uma voz que anuncia autoria no discurso. $\mathrm{O}$ protesto de um aluno frente ao discurso vertical evidencia a autoridade e reclama a autoria - turno 33. Nesse caso, o discurso tende a um duelo em que professora e alunos pretendem estabelecer, cada qual, a sua agenda. No entanto, a correção do questionário produz efeitos de monofonia quando uma voz apenas faz-se ouvir. O discurso monológico e o discurso polifônico permeiam a aula. Embora o discurso polifônico siga o caminho de rupturas e contestações, ele se apresenta de alguma maneira, preso ao sistema de domínio do conteúdo da aula. As palavras usadas pelos alunos estão diretamente ligadas à familiaridade, à ruptura de hierarquias, a autoria. Tais características só são possíveis pela utilização da linguagem rica em ambivalência e em duplicidade. Eis um fragmento da aula que expressa essa autoria da palavra e tentativa de compreensão que a professora e as crianças foram construindo da palavra "derivados" mediados pela prática do questionário:

\section{Episódio 3: Eu vou ler e vocês vão ouvir}

34. P: Quais os derivados do leite que vocês conhecem?

35. A: Professora en quero falar!

36. A: Pamela, fala um

37. A: Manteiga

38. P: João, fala outro

39. A: Óleo

40. P: Óleo é do leite? 
41. A: Óleo é dos vegetais

42. A: Bolo, professora

43. P: Bolo não, a gente usa leite no bolo, mas ele não é derivado do leite.

44. A: Pão, professora

45. $P: P \tilde{A O}$ N $\tilde{A O}$

46. $A$ : Pão de queijo

47. P: Não. Pão de queijo não. O leite entra para fažer o pão de queijo, mas ele não é o produto principal.

48. P: O principal, PRIN - CI - PAL, produto da manteiga é o quê??

49. A: O leite

50. P: Entenderam a diferença?

51. P: No caso do bolo o leite entra em pouca quantidade.

52. A: Chocolate é derivado

53. P: NÃO. O cacau é o principal produto.

54. A: Doce de leite

55. A: Leite em pó

56. A: Biscoito!!!

57. P: JA FALEI! Não é o principal produto. Ele entra na composição.

58. A: Bolo!

59. P: Já expliquei

60. A: Arroz doce, professora

61. P: Qual é o principal produto? Olha, O NOME JÁ ESTÁ FAL ANDO...

62. A: Arroz!

63. A: Doce!

64. P: Vamos ler o texto. Nesse texto a gente vai ver o leite desde a hora que o vaqueiro ordenha a vaca, até o momento que ele sai da fábrica.

65. P: Então, podemos ler agora?

66. P/As/: O leite....

67. P: AGORA, EU VOU LER E VOCÊS SÓ VÃO OUVIR!

\section{"EM TUDO OUÇO VOZES": SENTIDOS E SIGNIFICADOS QUE PERMEIAM A PRÁTICA DO QUESTIONÁRIO}

O apogeu da correção é atingido nesse fragmento, quando os alunos, em vez de submeter-se às regras arbitrárias do questionário, veem nessas regras um jogo para experimentar outras respostas para além da professora. Nesse momento, as múltiplas vozes e interpretações restituíram ao questionário seu contexto dialógico.

Um elemento relevante para a concretização do enunciado é sua característica responsiva, em função do qual Bakhtin constrói a ideia de compreensão. Se o enunciado é um elo da cadeia enunciativa, sua gênese se dá em função dos enunciados dos demais participantes da interação verbal, constituindo-se como espécie de resposta àquilo que já foi dito ou escrito. Assim, um outro traço fundamental do enunciado é seu caráter responsivo. 
$\mathrm{Na}$ perspectiva bakhtiniana, esse caráter responsivo se vincula à própria compreensão que é tomada como um processo ativo no qual a resposta é um elemento sempre presente. Para compreender o enunciado do outro, e nessa medida conferir-lhe significado, o sujeito se orienta no horizonte conceitual do interlocutor, opondo suas palavras às dele, ou seja,

'a cada palavra da enunciação que estamos em processo de compreender, fazemos corresponder uma série de palavras nossas, formando uma réplica. Quanto mais numerosas e substanciais forem [nossas palavras], mais profunda e real é a nossa compreensão. Assim, cada um dos elementos significativos e isoláveis de uma enunciação e a enunciação toda são transferidos nas nossas mentes para um outro contexto, ativo e responsivo' (Bakhtin, 1997, p. 132).

O próprio locutor produz o enunciado aguardando uma resposta de seu interlocutor, na forma de concordância, objeção, execução ou outra atitude responsiva, e isso se dá em razão de ele ter em mente a existência de enunciados anteriores aos quais seu enunciado responde. A compreensão é, portanto, uma forma de diálogo que se estabelece pela oposição e pela recontextualização de palavras. Esse é um outro traço do conceito de dialogia em Bakhtin.

O dialogismo se refere à relação entre um enunciado e outros que vão além das formas óbvias de uma conversa, mas também nas formas mais sutis e difusas do discurso. E o questionário emerge de um processo dialógico: da conversa entre professora e alunos ou alunos e alunos; de pessoas que permutam perguntas e respostas e que, de modo geral, se alimentam da intensidade um do outro. De acordo com Bakhtin:

"Viver significa tomar parte no diálogo: fazer perguntas, dar respostas, dar atenção, res-
ponder, estar de acordo, assim por diante. Desse diálogo, uma pessoa participa integral-
mente e no correr de toda a sua vida: com seus olhos, lábios, mãos, alma, espírito, com seu
corpo todo e com todos os seus feitos. Ela investe seu ser inteiro no discurso e esse dis-
curso penetra no tecido dialógico da vida humana, simpósio universal." (Bakhtin, 1981).

É a partir desses pressupostos que analisamos a correção do questionário, pois ainda que impere a voz da professora, as crianças vão construindo seus próprios significados, tentam dar sentido ao que está sendo dito recorrendo a contrapalavras em resposta às palavras da professora. As crianças participam desse diálogo vivo que é a busca de respostas ao questionário. Nessa tarefa, como um ato de fala, portanto, de negociação e constituição de sentidos, vive um conflito de vozes e, não um ato de simples decodificação ou interpretação. Nesse sentido, as respostas do questionário são profundamente dialógicas: suas contrapalavras não são ecos, não é repetição, mas modos de compreensão que abrem caminhos nessa cadeia infinita de enunciados.

No turno 34, o objeto de negociação é o conceito da palavra "derivado". E, apesar da pergunta mais uma vez induzir ao revozeamento, a questão que a professora propõe aos alunos não tem uma única resposta. Nesse fragmento, ainda 
que as vozes das crianças apareçam privadas de autoridade, não é inaudível. Ao contrário, se apresentam em coro dialógico e persuasivo. As crianças afirmam suas vozes fornecendo novos contextos, novas matizes. E é essa polifonia que instaura a questão dos diferentes sentidos e significados da palavra em sala de aula. Nesse caso, a pergunta: "Quais os derivados do leite que vocês conhecem?" abre várias possibilidades das crianças dialogarem com o conceito. Podemos afirmar que é a partir do turno 34 que se dá a tentativa de compreensão das crianças em relação à palavra “derivado". No turno 39, João responde à professora que óleo é derivado do leite. No turno 40, nota-se que a professora lança uma nova pergunta para levar o aluno à corrigir sua resposta. E quando ela enfatiza: "o óleo é do leite?" um aluno afirma no turno 41 que "óleo é dos vegetais" fica estabelecido para os alunos uma categoria - o que é dos vegetais não pode ser do leite. Isso parece ficar claro para as crianças, que nos turnos seguintes não citam mais produtos formados a partir dos vegetais. O conceito da palavra "derivado" vai se transformando à medida que as crianças procuram compreendê-la, dialogando com os conhecimentos que dipõem.

Para Vygotsky (1999), só existe significação quando o que significa para o sujeito penetra no mundo das significações do outro, e por ele é reconhecido. Dessa forma, só há significação se houver um outro, caso contrário, nada significa, é vazio de sentido. De fato, ao buscar os sentidos das palavras, os alunos se orientavam em direção à professora, buscavam os sentidos que ela atribuía à palavra. A multiplicidade dos sentidos e sua presença na construção de réplicas explicam melhor como são construídos os significados, segundo Bakhtin:

\footnotetext{
"Compreender a enunciação de outrem significa orientar-se em direção a ela, encontrar o seu lugar adequado no contexto correspondente. A cada palavra da enunciação que estamos em processo de compreender, fazemos corresponder uma série de palavras nossas formando uma réplica. Quanto mais numerosas e substanciais forem, mais profunda e real é a nossa compreensão." (BAKHTIN, 1992, p.132)
}

A compreensão em Bakhtin é vista como processo de construção de sentidos. Sentidos movediços que vão se transformando, gerando outros sentidos. A produção de sentidos emerge dessa relação viva e divergente entre uma consciência e outra. Portanto, a compreensão é sempre dialógica porque implica negociação de sentidos que se elabora em vista do outro.

A análise dos turnos 42 e 44 mostra que os alunos, no esforço de compreensão da palavra, entendem derivado como o alimento que resulta da mistura e não como um produto que deriva de outro. Pode-se entender o discurso produzido pelas crianças como o resultado de uma operação dedutiva em que a palavra "mistura" é tomada como significação da palavra "derivado". E como resultado "da mistura", o exemplo dado pelos alunos como derivado é o pão e o bolo. Apesar de a professora tentar explicar que o leite é usado para a fabricação do pão e do bolo, ela não compreende a luta que as crianças estão travando em torno do conceito.

As formulações de Vygotsky ensinam que o processo de formação de conceitos surge impregnado de ideias da experiência. Vygotsky chama atenção 
para a distinção entre sentido e significado da palavra: "O sentido de uma palavra é a soma de todos os eventos psicológicos que a palavra desperta em nossa consciência (...). O significado é apenas uma das zonas do sentido, a mais estável e precisa" (1993, p. 125). Para esse autor, a capacidade que os significados têm de transformar é muito importante para a construção dos sentidos, pois são os sentidos que vão configurar a construção de significados.

No turno 46, outra investida é feita por um aluno que responde que o pão de queijo é derivado do leite. Nesse caso, podemos supor que se perpetua a ideia de que qualquer produto no qual se usa o leite, então, é derivado, mas, nesse momento o aluno tenta um produto que tem "queijo" no nome. Nos turnos 54 e 55 evidenciamos que as crianças se remetem ao referente na tentativa de compreensão do signo. Os produtos doce de leite e leite em pó, por levarem leite no nome, são para os alunos "derivados" do leite. A professora introduz uma palavra estranha ao universo das crianças e elas dialogam com a palavra. Nessa perspectiva, as palavras - da professora e das crianças - estão ali, influenciando e sendo influenciadas pelos discursos que permeiam a aula. Isso demonstra que responder ao questionário vai além da troca de enunciados. Ele é construído em razão da relação com o sentido, a partir da compreensão de um enunciado. Responder ao questionário se inscreve, portanto, nesse ambiente polifônico de afirmação do outro, das várias vožes que são parte integrante do projeto de fala do sujeito. As crianças escutam a voz da professora e não representam essa voz como uma unidade, mas como um jogo de confrontações. Cabe aqui uma referência às palavras de Bakhtin:

\footnotetext{
"Na realidade, toda palavra comporta duas faces. Ela é determinada tanto pelo fato de que procede de alguém, como pelo fato de que se dirige para alguém. Ela constitui justamente o produto da interação do locutor e do ouvinte. (...) A palavra é uma espécie de ponte lançada entre mim e os outros. Se ela se apóia sobre mim numa extremidade, na outra apóia-se sobre meu interlocutor. A palavra é o território comum do locutor e do interlocutor" (BAKHTIN, 1999, p.113).
}

Diante da negativa da professora no turno 56, os alunos voltam a falar de produtos que resultam da mistura do leite e, mais tarde, no turno 62, prendem-se à palavra mais uma vez na tentativa de elaboração do significado. No turno 61, a explicação da professora sobre "derivado" diz uma coisa e significa outra. O nome "doce de leite" diz do resultado da mistura e não de derivado. A explicação da professora é limitada, não só pela definição errônea, mas, principalmente, por não considerar "a natureza intertextual da palavra: o fato de que um enunciado 'ecoa' o enunciado de outro". Não é pelo significado da palavra que as crianças poderiam construir o sentido, mas, ao contrário, pela contraposição dos sentidos gerados a partir da palavra. No discurso, a palavra tem duplo sentido: volta-se para o objeto do discurso como palavra comum e para o outro discurso.

Para trabalhar a linguagem científica, é preciso se voltar para a apropriação de significados, processo que ocorre na negociação de sentidos resultante da relação dialógica. É preciso, então, que o professor compreenda os sentidos que 
as crianças constroem para o objeto de estudo para que seja capaz de negociar os significados que os alunos atribuem aos conceitos científicos. Isso significa a afirmação e a negação, ao mesmo tempo, dos dois níveis de conhecimento cotidiano e o científico na construção do conhecimento, tendo, contudo, como referência imediata, durante todo o processo, o saber cotidiano do aluno.

Finalmente, no turno 64 a professora convida a todos para a leitura do texto. No turno 66, quando os alunos iniciam a leitura com a professora, ela os interrompe no turno 67 chamando a atenção de que eles só iriam ouvir. Como destaca Ducrot (apud Rojo, 2001), uma característica peculiar no discurso de sala de aula é o uso do dêitico de pessoa nós, aparentemente inclusivo, mas que não o é na medida em que a leitura não é coletiva e a professora, pelo lugar que ocupa, define que a leitura será realizada somente por ela. Mas, ainda que a professora tenha a última palavra, mesmo que as crianças sejam silenciadas, suas dúvidas e reflexões sobre o que é "derivado" perpetuam para além dos olhos e ouvidos da professora.

\section{CONSIDERAC̦ÕES FINAIS}

Este trabalho mostra que, como produto do incessante leva e traz, o questionário resiste a uma sistematização rígida. Evidencia que embora exista uma tentativa de controlar o discurso na sala de aula, os sentidos não são previamente determinados, pois dependem das histórias de vida dos interlocutores, de suas intenções, de suas preferências, além das circunstâncias materiais em que ocorre a enunciação. No princípio da aula, observamos que as crianças conhecem o discurso que deve ser produzido com a prática o questionário, mas, depois de um tempo, professora e crianças se perdem porque ambos desconhecem a multiplicidade de discursos que estão sendo produzidos.

Para cada pergunta do questionário, há uma tendência de fechamento dos sentidos em busca de um significado, um "ensinamento" do professor. No entanto, na maioria das vezes, não coincidem o ensino da professora com a aprendizagem das crianças. Em alguns momentos, os sentidos produzidos são distintos e até incompatíveis. Discutidas por Mortimer (1997), as interações discursivas em sala de aula ocorrem na tensão entre a tendência de fechamento de sentidos do discurso científico, buscando a univocidade, e a abertura de sentidos pelas vozes dos alunos. Nesse caso, duas funções são percebidas no discurso: a função dialógica e a função unívoca. Nesse padrão das interações discursivas em aulas de Ciências, o professor inicia o diálogo por meio de uma pergunta, o aluno responde, e o professor conclui. Esse padrão discursivo configura o gênero escolar. A forma como o professor conclui é determinante para caracterizar um discurso dialógico ou um discurso de autoridade. Se o fechamento pelo professor ocorre com sentido exclusivamente avaliativo, tende a um discurso de autoridade. Se, por outro lado, na réplica emitida pelo professor forem consideradas as palavras dos alunos, e a partir delas apontadas outras possibilidades, dentre as quais comparece a explicação científica, a interação discursiva se aproxima da dialogia. 
Os trabalhos de Silveira (1966), Mehan (1979) e Weissmann (1998) demonstram que através das atividades pedagógicas as relações estabelecidas colocam, desde o princípio, os papéis desempenhados por cada um e o lugar social de onde falam, ouvem e agem. Essa estrutura se impõe de tal forma que em pouco tempo de vivência na escola alunos e professoras assimilam seu papel: aprender/ ensinar, perguntar/responder.

A leitura desses trabalhos nos leva a pensar que se manifesta em sala de aula apenas o discurso oficial e monológico dominante na escola. Baseada no gestaltismo, Silveira (1966) ressalta o papel do questionário para a compreensão. Para a autora, essa prática sintetiza o conhecimento. Compreensão, nessa perspectiva, é síntese. Contrário a essa posição, Bakhtin postula que compreensão é trabalho de produção de sentidos. Segundo esse autor:

Compreender a enunciação de outrem significa orientar-se em direção a ela, encontrar o seu lugar adequado no contexto correspondente. A cada palavra da enunciação que estamos em processo de compreender, fazemos corresponder uma série de palavras nossas formando uma réplica. Quanto mais numerosas e substanciais forem, mais profunda e real é a nossa compreensão (BAKHTIN, 1992, p.132).

Nessa perspectiva, a compreensão implica mais do que a identificação do significado das palavras, os sentidos produzidos, as intenções que não se encontram explicitadas. Assim, a compreensão e, portanto, o questionário, não são uma síntese, não são um discurso monológico, mas um labirinto polifônico. Portanto, o questionário é sempre dialógico porque implica negociação de sentidos que se elabora em vista do outro.

Por outro lado, é importante pensar nos propósitos das interações que ocorrem no uso dessa estratégia e suas consequências para o (in)sucesso do processo ensino-aprendizagem. Podemos afirmar que mesmo que a resposta ao questionário possibilite a pluralidade de vozes, pode servir ao desenvolvimento de um discurso escolarizado quando essas vozes são silenciadas.

Concordamos com Mortimer e Scott (2003) sobre a importância da forma com que o professor intervém nas discussões em sala de aula e vamos além destacando a importância das perguntas, do uso do questionário nas aulas de Ciências. As perguntas oriundas de um questionário podem desempenhar uma importante função epistêmica se constituírem modo de aprendizagem pela reconstrução dos conhecimentos dos que nele se envolvem. Nas aulas de Ciências, o questionário pode ser um recurso importante para compreender o sentido profundo do uso da linguagem, pois

Falar ciência não significa simplesmente falar sobre a ciência. Significa fazer ciência por meio da linguagem. Falar ciência significa observar, descobrir, comparar, classificar, analisar, discutir, formular hipóteses, teorizar, questionar, desafiar, argumentar, planejar experimentos, seguir procedimentos, julgar, avaliar, decidir, concluir, generalizar, informar, escrever, ler e ensinar por meio da linguagem da ciência (LEMKE, 1997, p. 11). 
Assim, realizar uma tarefa com questionário pode significar conhecer a perspectiva de outros pela resposta que cada um constrói e, com isso, contribuir para buscar novos entendimentos das questões estudadas e reconstruir argumentos, fundamentando-os melhor e qualificando-os pelo intercâmbio com outras vozes, especialmente de autores especializados nos temas investigados. Assumir-se sujeito das respostas é compreender a função de questionário como instrumento de pensar, como ferramenta de produção de sentidos, pois as legítimas perguntas põem em movimento o pensamento de quem responde, estabelecendo relações entre seus próprios conhecimentos e aqueles expressos nos textos, sempre no sentido de reconstrução de conhecimento já constituído. Pensar o questionário na concepção de um "falar ciência" é oportunizar aos alunos a apropriação da linguagem da ciência, assumindo-se sujeitos das transformações sociais.

\section{NOTAS}

\footnotetext{
${ }^{1}$ Silveira (1966), Weissmann (1998), Barros, Susana, Losada e Cristina (2001).

${ }^{2} \mathrm{Na}$ transcrição dos eventos, usamos o padrão ortográfico. Utilizamos a seguinte legenda: (...) para pausas e letras maiúsculas para ênfases.
}

\section{REFERÊNCIAS BIBLIOGRÁFICAS}

ALMEIDA, Sheila Alves. Ver o invisivel: o olhar das professoras sob uma experiência de ensinar e aprender com as atividades de conhecimento físico nos ciclos iniciais. 2005. Dissertação (Mestrado em Educação) - Faculdade de Educação, Universidade Federal de Minas Gerais, Belo Horizonte, 2005.

CANDELA, Antonia. Ciencia en el aula: los alumnos entre Ia argumentación. y el consenso. México/ MEX: Paidós Educador, 1999.

BAKHTIN, Mikhail. Estética da Criação Verbal. Tradução por Maria Ermantina Galvão G.Pereira. São Paulo: Martins Fontes. 1997.

Marxismo e Filosofia da Linguagem. Tradução por Michel Lahud e Yara Frateschi Vieira. São Paulo: Hucitec. 1995.

BRAIT, B. O processo interacional. In: PRETI, Dino (org.) Análise de textos orais. 4. ed. São Paulo: Humanitas, 1999.

BRASIL. Secretaria de Educação Fundamental. Parâmetros Curriculares Nacionais: ciências naturais. Brasília: MEC, SEF, 1998.

CAZDEN, Courtney B. Classroom Discourse: The Language of Teaching and Learning. 2. ed. Portsmouth, USA: Heinemann, 2001.

EMERSON, C. O mundo exterior e o discurso interior, Bakhtin, Vygotisky e a internalização da língua. In: DANIELS, H. (Org.). Uma introdução a Vygotsky. São Paulo: Loyola, 2002.

GUIDO, L. F. E. A Evolução Conceitual na Prática Pedagógica do Professor de Ciências das Séries Iniciais. 1996. Dissertação (Mestrado em Educação). Faculdade de Faculdade de Educação, Universidade de Campinas, Campinas-SP, 1996.

JIMÉNEZ Aleixandre M.P., Bugallo Rodríguez A. e Duschl R.A. (2000) 'Doing the lesson' or 'Doing Science’: Argument in High School Genetics. Science Education, [s.l] v. 84, 2000. 
LEMKE, J. (1990) Talking Science. Language, Learning and Values. Norwood, NJ: Ablex, 1990.(Traducido como Aprender a hablar Ciencia. Lenguaje, aprendizaje, valores. Barcelona: Paidós,1997).

MEHAN, H. Learning Lessons: social organization in the classroom. Cambridge, MA: Harvard Press, 1979.

MACEDO, M.S.N.; MORTIMER, E.F.; GREEN, J.A constituição das interações em sala de aula e o uso do livro didático: análise de uma prática de letramento no primeiro ciclo. Revista Brasileira de Educação, Rio de Janeiro, nº 25, Jan/Fev/Mar/Abr. 2004.

MERCER, N. Language, Education and the Guided Construction of Knowledge. In: ENCONTRO SOBRE TEORIA E PESQUISA EM ENSINO DE CIÊNCIAS: LINGUAGEM, CULTURA E COGNIÇÃO, REFLEXÕES PARA O ENSINO DE CIÊNCIAS, 1997, Águas de Lindóia. Anais... Águas de Lindóia, SP: SBF, 1997.

MOLINA, A. El modelo didáctico del maestro y la clase de ciencias en la básica primaria. In: ENCONTRO NACIONAL DE PESQUISA EM ENSINO DE CIÊNCIAS, LINGUAGEM, CULTURA E COGNIÇÃO, REFLEXÕES PARA O ENSINO DE CIÊNCIAS ,1997, Águas de Lindóia. Anais... Aguas de Lindóia, SP: Sociedade Brasileira de Física, 1997.

MORTIMER, Eduardo F.; SCOTT, Phillip H. Making meaning in secondary science classrooms. Maidenhead, UK: Open Univ. Press., 2003.

OSBORNER, R.; FREYBERG, P. El Aprendiraje de las Ciencias: implicaciones de la ciencia de los alumnos. Madrid: Narcea, S. A . Ediciones, 1991.

ROJO, Roxane Helena Rodrigues. Gêneros do discurso no circulo de Bakbtin - ferramentas para a análise transdiciplinar de enunciados em dispositivos e práticas didáticas. Disponível em: $<$ http://www3.unisul.br/ paginas/ensino/pos/linguagem/cd/Port/117.pdf>. acesso em: 24 de agosto de 2009.

SILVEIRA, Juracy. Leitura na escola primária. Rio de Janeiro: Conquista, 1966.

TODOROV, T. Os gêneros do discurso. São Paulo: Martins Fontes, 1980.

VYGOTSKY Lev S. Pensamento e linguagem. Tradução por Jeferson Luiz Camargo. São Paulo: Martins Fontes. 1993. A formação social da mente: o desenvolvimento dos processos psicológicos superiores. Tradução por José Cipolla Neto et al. São Paulo: Martins Fontes, 1994.

WEISMANN, H. O que ensinam os professores quando ensinam Ciências Naturais e o que dizem querer ensinar. In: WEISSMANN, Hilda (Org.). Didática das ciências naturais: contribuições e reflexões. Porto Alegre: ArtMed, 1998.

WELLS, G. (org). Creating communities of inquiry. Toronto, Canadá: Portsmouth, OISE Press e Heinemann, [199?]. 